\title{
Genome-wide Mapping for Stripe Rust Resistance Loci in Common Wheat Cultivar Qinnong 142
}

\author{
Qingdong Zeng, Jianhui Wu, Shengjie Liu, Xianming Chen, Fengping Yuan, Pingping Su, Qilin Wang, Shuo Huang, Jingmei Mu, \\ Dejun Han, ${ }^{\dagger}$ and Zhensheng Kang, ${ }^{\dagger}$ State Key Laboratory of Crop Stress Biology for Arid Areas, Northwest A\&F University, Yangling, \\ Shaanxi 712100, P.R. China; and X. M. Chen, Wheat Health, Genetics, and Quality Research Unit, Agricultural Research Service, U.S. De-
} partment of Agriculture, Pullman, WA 99164; and Department of Plant Pathology, Washington State University, Pullman, WA 99164, U.S.A.

\begin{abstract}
Stripe rust caused by Puccinia striiformis f. sp. tritici threatens worldwide wheat production. Growing resistant cultivars is the best way to control this disease. Chinese wheat cultivar Qinnong 142 (QN142) has a high level of adult-plant resistance to stripe rust. To identify quantitative trait loci (QTLs) related to stripe rust resistance, we developed a recombinant inbred line (RIL) population from a cross between QN142 and susceptible cultivar Avocet S. The parents and $165 \mathrm{~F}_{6}$ RILs were evaluated in terms of their stripe rust infection type and disease severity in replicated field tests with six site-year environments. The parents and RILs were genotyped with

single-nucleotide polymorphism (SNP) markers. Four stable QTLs were identified in QN142 and mapped to chromosome arms 1BL, 2AL, 2BL, and 6BS. The 1BL QTL was probably the known resistance gene $\mathrm{Yr} 29$, the $2 \mathrm{BL}$ QTL was in a resistance gene-rich region, and the $2 \mathrm{AL}$ and 6BS QTLs might be new. Kompetitive allele specific polymerase chain reaction markers developed from the SNP markers flanking these QTLs were highly polymorphic in a panel of 150 wheat cultivars and breeding lines. These markers could be used in marker-assisted selection for incorporating the stripe rust resistance QTL into new wheat cultivars.
\end{abstract}

Wheat (Triticum aestivum L.) is a major crop throughout the world. Stripe rust (yellow rust) caused by Puccinia striiformis Westend. f. sp. tritici Erikss. occurs in almost all wheat-producing regions. This disease causes significant economic losses in terms of reduced grain production and the expenses incurred for disease management (Beddow et al. 2015; Hovmøller et al. 2010; McIntosh et al. 1995). In general, stripe rust causes yield losses of 5 to $25 \%$ in susceptible wheat cultivars, but it may cause complete yield losses in severe epidemics (Chen 2005; Wellings 2011). As the largest stripe rust epidemic region throughout the world, China frequently suffers severe yield losses (Chen 2014; Li and Zeng 2002; Wan et al. 2007). Growing resistant cultivars is an economical, effective, and environmentally friendly way to control this disease (Li and Zeng 2002; McIntosh et al. 1995; Wiesner-Hanks and Nelson 2016).

Both all-stage resistance (ASR) and adult-plant resistance (APR) have been used for breeding wheat cultivars with resistance to stripe rust (Chen 2013). ASR often confers complete resistance during all growth stages and is easy to select during the breeding process, but it is mostly race-specific and not durable (Johnson 1981; McDonald and Linde 2002). By contrast, APR usually confers partial resistance during the adult-plant stage, and it is mostly race-nonspecific and more durable. However, APR can be relatively difficult to incorporate into new cultivars compared with ASR (Chen 2013; Park and McIntosh 1994). Many wheat cultivars that exhibit durable resistance possess

${ }^{\dagger}$ Corresponding authors: Dejun Han; E-mail: handj@nwsuaf.edu.cn and Zhensheng Kang; E-mail: kangzs@nwsuaf.edu.cn

Qingdong Zeng and Jianhui Wu contributed equally to this work.

Funding: This study was financially supported by the National Science Foundation for Young Scientists of China (grant no. 31701421), China Postdoctoral Science Foundation funding (2017M623260), Earmarked Fund for Modern Agro-industry Technology Research System (No. CARS-3-1-11), and National Natural Science Foundation of China (31371924).

*The $\boldsymbol{e}$-Xtra logo stands for "electronic extra" and indicates that seven supplementary tables are published online.

Accepted for publication 28 August 2018.

(c) 2018 The American Phytopathological Society
APR (Boyd 2005; Chen 2013; McIntosh 1992; Navabi et al. 2005; Singh et al. 2005). Over 300 genes or quantitative trait loci (QTLs) for either ASR or APR to $P$. striiformis $\mathrm{f}$. sp. tritici in various wheat genotypes have been mapped to all 21 chromosomes (Maccaferri et al. 2015; McIntosh et al. 2016, 2017; Rosewarne et al. 2013; Wang and Chen 2017). However, many of the ASR genes are no longer effective against the current $P$. striiformis $\mathrm{f}$. sp. tritici populations, and many of the APR QTLs have only small effects. Moreover, not all of these genes or QTLs have molecular markers that can be used for marker-assisted selection (MAS) in breeding programs. Therefore, more resistance genes or QTLs and suitable user-friendly markers should be identified.

It is important to map QTLs and to identify closely linked markers to combine with resistance QTLs in wheat cultivars. During the last 20 years, different types of molecular markers have been developed, such as simple sequence repeat (SSR) (Röder et al. 1998) and resistance gene analog polymorphism (Chen et al. 1998), and used for mapping wheat genes (Ren et al. 2012a, b; Rosewarne et al. 2013; Zhou et al. 2014). These polymerase chain reaction (PCR) markers have been applied successfully in MAS, but the densities of these types of markers are about 10-20 cM per marker (Semagn et al. 2010; Yan et al. 2006). Thus, more cost-effective markers and high-throughput genotyping platforms are still required for MAS (St. Clair 2010; Yang et al. 2015). More recently, single nucleotide polymorphism (SNP) markers have been developed, which are abundant, mostly codominant, and distributed throughout the genome, and applied in studies of wheat genetics (Allen et al. 2013; Rasheed et al. 2016; Wu et al. 2017, 2018). SNP markers have many advantages for high-throughput genotyping, including their low cost, allele specificity, and high efficiency (Colasuonno et al. 2014; Gupta et al. 2008; Long et al. 2017; Semagn et al. 2014). SNP chips containing different numbers of markers, including $9 \mathrm{~K}, 15 \mathrm{~K}, 35 \mathrm{~K}, 50 \mathrm{~K}, 55 \mathrm{~K}, 90 \mathrm{~K}, 660 \mathrm{~K}$, and $820 \mathrm{~K}$, are commercially available, and some of these chips have been used widely to identify genes for various traits in wheat (Allen et al. 2017; Cavanagh et al. 2013; Jia and Zhao 2016; Muqaddasi et al. 2017; Wang et al. 2014; Winfield et al. 2016).

Wheat cultivar Qinnong 142 (QN142) developed from the cross of Zhengmai 8329/87135-2-1-2-9 by the Baoji Academy of Agricultural Sciences, Shaanxi, China, is a high-yielding cultivar with resistance to stripe rust. This cultivar has been grown in the Yellow and Huai River Valley wheat zone of China since 2005, and it has been widely used as a parent in breeding programs. We have tested QN142 
for resistance to stripe rust in fields located in Shaanxi and Gansu provinces since 2008 and found that it is consistently resistant at the adult-plant stages (Zeng et al. 2014). However, the genetic basis of its stripe rust resistance is unknown. Thus, the objectives of this study were (i) to characterize and dissect the genetic structure of stripe rust resistance in an Avocet $\mathrm{S}(\mathrm{AvS}) \times \mathrm{QN} 142$ recombinant inbred line (RIL) population, (ii) to identify QTLs for APR to stripe rust across multiple environments using molecular markers, (iii) to assess the additive effects of the QTLs on reducing stripe rust severity, and (iv) to develop kompetitive allele-specific PCR (KASP) markers for the QTLs for use in MAS.

\section{Materials and Methods}

Wheat materials. In total, $165 \mathrm{~F}_{6}$ and $\mathrm{F}_{7}$ RILs developed from a single $\mathrm{F}_{1}$ plant of AvS $\times$ QN142 through single-seed descent were used for genetic mapping. The resistant parent QN142, originally from the China Agriculture Research System, and the susceptible parent AvS, originally from Australia, were used as references in all phenotypic and genotypic experiments. Wheat cultivars Mingxian 169 (MX169) and Xiaoyan 22 (XY22) were used as susceptible checks in the field experiments. A panel comprising 150 wheat cultivars and breeding lines from the Yellow and Huai River Valley wheat zone was used to validate the KASP markers flanking the identified QTL or to determine the marker polymorphisms.

Seedling tests. Seedling tests were conducted under controlled greenhouse conditions to characterize the stripe rust ASR in QN142. Chinese $P$. striiformis f. sp. tritici race CYR23 was used in the tests, and its avirulence/virulence pattern was reported by $\mathrm{Wu}$ et al. (2016). For the seedling tests, 10 to 15 plants of AvS, QN142, and their RILs were grown in $9 \times 9 \times 9 \mathrm{~cm}$ pots. Details of the inoculation procedure were described previously by Wu et al. (2018). The infection types were recorded at 18 to 21 days after inoculation using a scale that ranged from 0 to 9 (Line and Qayoum 1992; Wan and Chen 2014). Plants with infection type (IT) ranging from 0 to 6 were considered resistant, and plants with IT from 7 to 9 were considered susceptible. All tests were conducted three times in order to confirm and clarify the IT.

Field tests. The parents and $\mathrm{F}_{6}$ RIL population, as well as MX169 and $\mathrm{XY} 22$, were grown in fields at Yangling, Shaanxi province $\left(34^{\circ} 17^{\prime} \mathrm{N}, 108^{\circ} 04^{\prime} \mathrm{E}\right.$, altitude $\left.519 \mathrm{~m}\right)$, Tianshui, Gansu province $\left(34^{\circ} 27^{\prime} \mathrm{N}, 105^{\circ} 56^{\prime} \mathrm{E}\right.$, altitude $\left.1,697 \mathrm{~m}\right)$, and Jiangyou, Sichuan province $\left(31^{\circ} 53^{\prime} \mathrm{N}, 104^{\circ} 47^{\prime} \mathrm{E}\right.$, altitude $\left.571 \mathrm{~m}\right)$ during the $2015-2016$ and 2016-2017 cropping seasons. The fields at Yangling were inoculated at the jointing stage by spraying a mixture of urediniospores from the prevalent races CYR32 and CYR33 suspended in liquid paraffin (1:300) onto the susceptible checks planted as spreader rows. The experiments in Tianshui and Jiangyou were conducted under natural infection with $P$. striiformis $\mathrm{f}$. sp. tritici because these locations were in the "hotspot" stripe rust regions. All of the experiments were arranged according to a randomized complete block design with two replicates in the 2015-2016 growing season and three replicates in the 2016-2017 growing season. Thirty seeds from each line were planted in a $120-\mathrm{cm}$ row in each replicate with a $30-\mathrm{cm}$ space between rows. IT and disease severity (DS) were scored for each row at 18-20 days postflowering when the stripe rust severity levels in MX169, AvS, and XY22 reached 90 to $100 \%$ around 15-20 May at Yangling, 10-15 June at Tianshui, and 10-15 April at Jiangyou. The IT data were recorded based on the scale from 0 to 9 mentioned above, and the DS data were scored with the modified Cobb scale (Peterson et al. 1948). For each line, the score was recorded at least twice or more, and the IT data and the last set of DS data treated as the maximum DS (MDS) were used for phenotypic and QTL analyses.

Phenotypic analysis. Analyses of variance (ANOVAs) were conducted using the IT and MDS data to determine significant differences among RILs and environments. ANOVA and Pearson's correlation coefficient analyses were conducted with the AOV function in the QTL IciMapping (version 4.1) software with the default parameters. The broad sense heritability $\left(h_{b}^{2}\right)$ of stripe rust resistance was estimated with the following formula:

$$
h_{b}^{2}=\frac{\sigma_{g}^{2}}{\sigma_{g}^{2}+\left(\sigma_{g \mathrm{e}}^{2} / e\right)+\left(\sigma_{\varepsilon}^{2} / r e\right)}
$$

where $\sigma_{g}^{2}$ represents genetic variance, $\sigma_{g e}^{2}$ represents the genotype (line) $\times$ environment interaction variance, $\sigma_{\varepsilon}^{2}$ represents the residual error, and $e$ and $r$ are the numbers of environments and replicates, respectively. The minimum number of QTLs was also estimated using Wright's method (Wright 1968): $n=(\mathrm{GR})^{2} / 4.27\left(\sigma_{g}^{2}\right)$, where GR comprises the phenotype ranges of the RILs multiplied by the narrow sense heritability, $\sigma_{g}^{2}$ is the genetic variance of the RIL population, and 4.27 was used as an inbreeding index for the $F_{6}$ generation, as described by Ren et al. (2017).

DNA extraction and marker genotyping. DNA was extracted from fresh leaves of the parents and $F_{6}$ RILs sampled at the jointing stage from the field in Yangling according to the method described by Song et al. (1994). The RILs and parents were genotyped at the CapitalBio Corporation (Beijing, China) using $35 \mathrm{~K}$ and $660 \mathrm{~K}$ iSelect SNP arrays. Low-quality SNPs with more than $10 \%$ missing values and major allele frequencies above $95 \%$ were removed. In addition, 1,375 SSR markers (Somers et al. 2004) selected to cover the genome were screened for polymorphic markers between the resistant and susceptible parents. The sequences of the SSR primers were acquired from the GrainGenes website (https://wheat.pw.usda.gov/GG3/), and the primers were synthesized by Invitrogen Trading Co. (Shanghai, China). Polymorphic SSR markers were used to genotype the RIL population according to the method described by Wu et al. (2017). The sequences of the 660K SNP markers were provided by Jizeng Jia, Chinese Academy of Agricultural Sciences.

Linkage map construction and QTL mapping. The SNP and SSR markers were tested for segregation using the $\chi^{2}$ test. Markers that differed significantly from a one-locus segregation ratio were excluded. Redundant markers with identical segregation were first binned using the BIN function in QTL IciMapping version 4.1 (Meng et al. 2015; Wang 2009). One marker was chosen to represent each bin based on the least amount of missing data or selected randomly if the markers had the same number of missing values. The filtered markers were then used to construct linkage maps with the MAP function in QTL IciMapping version 4.1, and the linkage groups were drawn using Mapchart version 2.3 (Voorrips 2002). To finalize the linkage map, marker ordering and ripping were performed using the RECORD and COUNT algorithms, respectively. The positions of the linkage groups on wheat chromosomes were determined based on both previously published maps (Sourdille et al. 2004) and 35K integrated maps (Allen et al. 2017).

The inclusive composite interval mapping (ICIM) of additive functionality in IciMapping was used to detect QTLs based on the mean IT and MDS scores in each environment. The threshold logarithm of odds (LOD) score for declaring QTLs was determined by permutation tests. The parameters used for QTL mapping and characterization were the same as those described in a previous study (Wu et al. 2017). The effects of each QTL and all of the detected QTLs were estimated as the phenotypic variance explained using ICIM.

Conversion of SNPs to KASP markers. The flanking SNP markers linked to the stable QTLs were converted into KASP markers for use in MAS during wheat breeding to obtain stripe rust-resistant cultivars. Briefly, the sequences of the flanking SNP markers were uploaded to PolyMarker (http://polymarker.tgac.ac. uk/) (Ramirez-Gonzalez et al. 2015), and the sequences of only the chromosome-specific markers were synthesized and used as KASP primers. All of the KASP markers with polymorphisms between AvS and QN142 were used to genotype the RIL population and the panel of 150 wheat cultivars or breeding lines according to the procedure described by Wu et al. (2017).

Haplotype analysis. To obtain the genomic locations of all the SNPs, BLASTn (E value 1e-10) was performed using the newest Chinese Spring sequence (IWGSC RefSeq version 1.0) as a reference, with an $\mathrm{E}$ value threshold of $10^{-5}$. According to the deduced regions of QYrqin.nwafu-2AL and QYrqin.nwafu-6BS, the 660K SNP 
genotype data in the target regions were used for haplotype analysis. Owing to limitations caused by various factors, we only tested AvSYr32NIL carrying Yr32 on chromosome 2AL (Eriksen et al. 2004) for comparison with QYrqin.nwafu-2AL, and wheat cultivars Stephens (Yr78) (Santra et al. 2008), RSL65 (Yr36) (Fu et al. 2009), and Pingyuan 50 (QYrpi.caas.3) (Lan et al. 2010) with the genes or QTLs on chromosome 6BS for comparison with QYrqin.nwafu-6BS.

\section{Results}

Race-specific all-stage resistance. When race CYR23 was tested at the seedling stage, QN142 exhibited resistance (IT = 1) and AvS was susceptible $(I T=9)$. The RIL population segregated with various ITs (Supplementary Table S1). The classification of the lines into resistant (IT = 0-6) and susceptible (IT = 7-9) groups suggested the presence of two genes for resistance to CYR23. Because two genes were indicated, QTL analysis was used to map the genes that conferred race-specific ASR. Two QTLs were detected on chromosome arms 1DS and 4AL by ICIM analysis.
Adult-plant responses to stripe rust. In all of the field experiments, QN142 was always resistant (IT $=1-3$, MDS $<20 \%$ ) and AvS was susceptible (IT $=9$, DS $>90 \%$ ) (Table 1, Fig. 1). The mean IT values for the RIL population ranged from 4.2 to $5.6 \%$, and the mean MDS values ranged from 39.7 to $56.9 \%$ in the three locations during 2015-2017 (Table 1). The frequency distributions of the IT and MDS classes among the RILs exhibited continuous variation with approximately normal distributions across the six environments (Fig. 1), thereby suggesting the quantitative inheritance of APR to stripe rust. The narrow-sense heritability of the stripe rust severity ranged from 0.86 to 0.93 in the different environments. The calculations using Wright's method (Wright 1968) indicated the presence of three to four APR genes (Table 1). The Pearson's correlation coefficients $(r)$ for IT and MDS in the RILs among the six field environments ranged from 0.76 to 0.89 , and they were all significant $(P<0.001$, Table 2$)$. These findings indicate that the expression of these four QTLs was consistent among the different environments with different weather conditions and $P$. striiformis f. sp. tritici races.

Table 1. Summary of the adult-plant stripe rust responses by the Avocet S (AvS) $\times$ Qinnong 142 (QN142) recombinant inbred line (RIL) population during the 2015-2016 and 2016-2017 cropping seasons in Yangling, Tianshui, and Jiangyou ${ }^{\mathrm{a}}$

\begin{tabular}{|c|c|c|c|c|c|c|c|c|}
\hline \multirow[b]{2}{*}{ Environment ${ }^{\mathbf{b}}$ (location, year) } & \multirow[b]{2}{*}{ AvS } & \multirow[b]{2}{*}{ QN142 } & \multicolumn{3}{|c|}{ RIL population } & \multirow[b]{2}{*}{$\sigma_{g}^{2}$} & \multirow[b]{2}{*}{$h_{b}^{2}$} & \multirow[b]{2}{*}{ Genes $^{c}$} \\
\hline & & & No. of RILs & Range & Mean & & & \\
\hline \multicolumn{9}{|l|}{ Infection type } \\
\hline YL2016 & 9.0 & 0.5 & 165 & $0.8-8.5$ & 4.3 & 3.2 & 0.89 & - \\
\hline TS2016 & 9.0 & 3.0 & 164 & $1.8-8.8$ & 5.2 & 2.4 & 0.80 & - \\
\hline JY2016 & 9.0 & 2.0 & 165 & $1.8-8.9$ & 5.1 & 1.6 & 0.86 & - \\
\hline YL2017 & 8.7 & 1.0 & 165 & $1.0-8.3$ & 4.2 & 3.5 & 0.93 & - \\
\hline TS2017 & 9.0 & 2.2 & 165 & $1.7-8.2$ & 5.6 & 1.3 & 0.90 & - \\
\hline JY2017 & 8.0 & 2.0 & 165 & $1.3-8.5$ & 5.2 & 2.2 & 0.88 & - \\
\hline \multicolumn{9}{|l|}{ Maximum disease severity } \\
\hline YL2016 & 90.0 & 1.0 & 165 & $1.0-95.0$ & 39.7 & 420.7 & 0.92 & 4.2 \\
\hline TS2016 & 90.0 & 7.5 & 164 & $5.5-100.0$ & 50.2 & 423.4 & 0.89 & 3.9 \\
\hline JY2016 & 100.0 & 10.0 & 165 & $5.0-100.0$ & 53.8 & 480.3 & 0.91 & 3.6 \\
\hline YL2017 & 93.3 & 3.3 & 165 & $5.0-98.3$ & 46.7 & 447.8 & 0.93 & 3.9 \\
\hline TS2017 & 100.0 & 18.3 & 165 & $10.0-95.5$ & 56.6 & 340.4 & 0.90 & 4.1 \\
\hline JY2017 & 100.0 & 16.7 & 165 & $10.0-91.7$ & 56.9 & 321.7 & 0.90 & 3.9 \\
\hline
\end{tabular}

${ }^{\mathrm{a}} \sigma_{g}^{2}$ represents genetic variance, and $h_{b}^{2}$ represents broad sense heritability.

b YL, TS, and JY denote Yangling, Tianshui, and Jiangyou, respectively, and 2016 and 2017 represent the RIL populations grown during the 2015-2016 and 2016-2017 cropping seasons, respectively.

${ }^{c}$ A dash (-) indicates gene numbers were not estimated with the infection type data using Wright's method (Wright 1968).

A

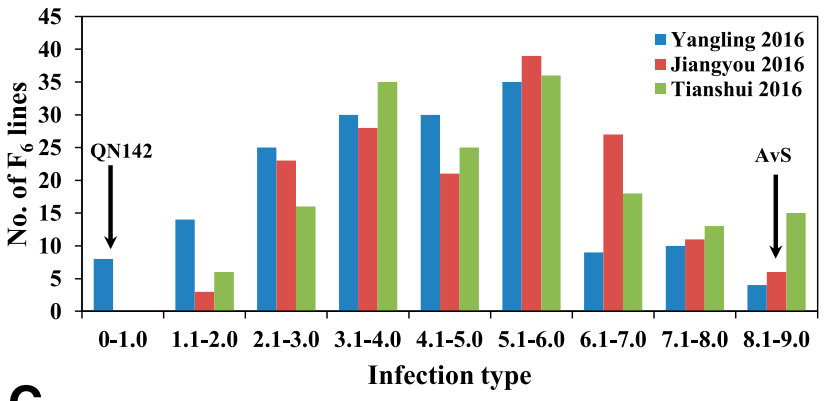

C

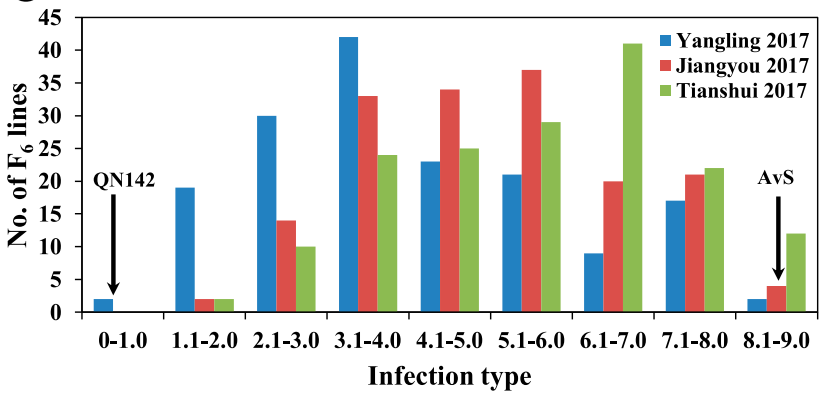

B

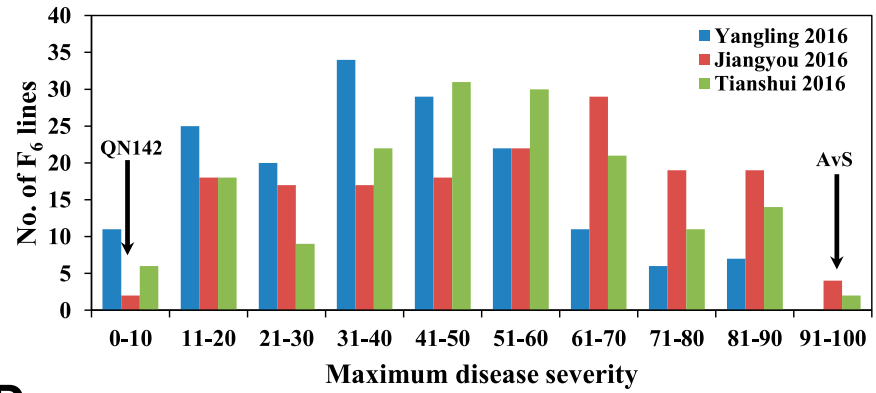

D

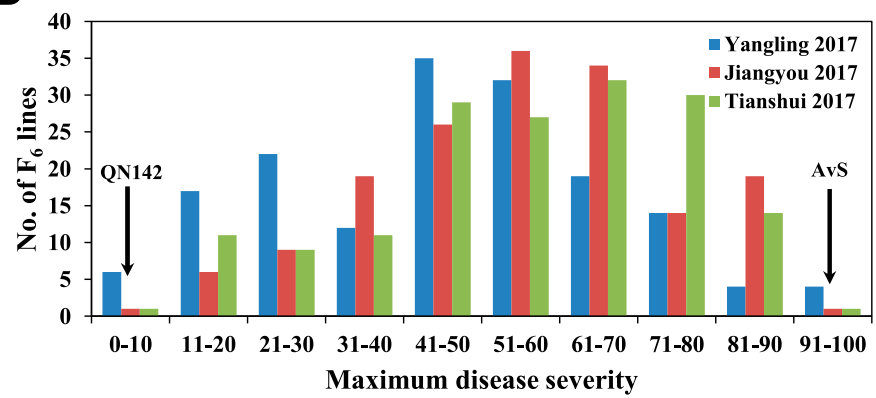

Fig. 1. Frequency distributions of the mean infection type and maximum disease severity for the 165 recombinant inbred lines from Avocet $S$ (AvS) $\times$ Qinnong 142 (QN142) evaluated in Yangling, Jiangyou, and Tianshui during 2015-2016 (A and B) and 2016-2017 (C and D). The values for the parents AvS and QN142 are indicated by arrows. 
Linkage groups. The parental lines and 165 RILs were genotyped with SSR markers and the 35K SNP array. Among the 1,375 SSR markers, 89 were polymorphic. Among the 35,143 SNPs, 7,996 were polymorphic between the parents. Among the polymorphic SNPs, 2,819 were removed because more than $10 \%$ of the data were missing and they exhibited severe segregation distortion for a single locus $(P<0.001)$ in the RIL population. The remaining 5,177 SNPs (Supplementary Table S2) fell into 1,456 bins, and 3,731 SNPs were redundant. Similarly, 35 SSR markers had distorted segregation ratios $(P<0.05)$ according to the $\chi^{2}$ tests based on the expected $1: 1$ ratio. The 1,456 SNPs and 54 SSR markers that satisfied a ratio of $1: 1$ and that represented different bins were used for constructing linkage groups. In total, 18 SSR markers and 45 SNP markers were unlinked. The final 36 linkage groups comprised 1,411 SNP and 34 SSR markers, and they spanned a total of $3,303.9 \mathrm{cM}$. The linkages in the A, B, and D genomes included 515 (35.6\%), 714 (49.4\%), and $216(15.0 \%)$ markers, respectively, which covered lengths of $1,194.4,1,274.5$, and $835 \mathrm{cM}$, with average marker densities of 2.3, 1.8, and $3.9 \mathrm{cM}$. Chromosomes 1B, 2A, 2B, 3B, 3D, 4D, 5A, $6 \mathrm{~B}$, and 7A each had one linkage group; 1D, 3A, 4A, 4B, 6A, 6D, and 7D each had two linkage groups; $1 \mathrm{~A}$ and 5D each had three linkage groups; 2D had four linkage groups; and 5BL/7BL and 5BS/7BS had translocations (Supplementary Tables S3 and S4). Only the linkage groups with significant stripe rust resistance QTLs are shown in Figure 2.

Identified QTLs. For the field tests, the QTLs that could be detected based on both IT and MDS data across the six environments and in the combined analysis were considered stable. Four stable QTLs were identified on 1BL, 2AL, 2BL, and 6BS, which were designated as QYrqin.nwafu-1BL, QYrqin.nwafu-2AL, QYrqin.nwafu$2 B L$, and QYrqin.nwafu-6BS, respectively. All of the QTLs were significant and contributed by the resistant parent QN142. On average, QYrqin.nwafu-1BL explained 15.7 and $19.7 \%$ of the phenotypic variation in IT and MDS, respectively. This QTL was mapped to a 10.04-cM region flanked by SNP markers $A X-95139868$ and $A X$-94885318. QYrqin.nwafu-2AL was significant at a threshold LOD value of 3.0 , and it explained 8.3 to $19.8 \%$ of the phenotypic variation in all environments. This QTL was mapped to a 7.9-cM region flanked by SNP markers $A X-94655393$ and $A X-94895021$ with SSR marker Xwmc170 within this region. The largest effect QTL, QYrqin.nwafu-2BL, located in a 1.4-cM interval flanked by SNP markers $A X-94507002$ and $A X-94562871$, explained 18.3 to $39.1 \%$ of the phenotypic variation in all environments. The second largest effect QTL, QYrqin.nwafu-6BS, explained 13.5 to $31.0 \%$ of the phenotypic variance, and it was located in the SNP marker interval of 0.3 cM between $A X-95235011$ and $A X-95188301$ (Table 3, Fig. 2).

Stripe rust responses of RILs with different QTL combinations. To investigate the effects of the QTLs on the stripe rust response, the 165 RILs were divided into genotypic groups based on the presence of the closest markers to the four QTLs for APR (Supplementary Table S6). These genotypes were further grouped into five groups based on the number of potential QTLs. The mean IT and MDS values for the five groups are shown in Figure 3. The lines with four QTLs had IT values of 1.3 to 2.4 and MDS values ranging from 8.4 to $18.2 \%$ across the six environments, which were similar to those of the resistant parent (Fig. 3B; Supplementary Table S5). In general, the lines with three QTLs were more resistant than those with two QTLs, which had better resistance than those with one QTL. This result was consistent with the three to four QTLs that conferred resistance in the RIL population estimated using Wright's method (Table 1). The RILs without any QTLs were highly susceptible (IT $=8-9, \mathrm{DS}=85$ to $95 \%$ ) but not significantly different from the susceptible parent. This was also supported by the significant additive effects $(P<0.01)$ among the QTLs obtained using the BIP function with the QTL IciMapping version 4.1 software.

KASP markers. Among the 47 SNP markers close to the four QTLs for APR with flanking sequences submitted to PolyMarker, 16 chromosome-specific SNPs were selected for conversion into KASP markers. After screening in the parents to confirm their polymorphisms, 8/16 markers failed to distinguish between the parents. Each QTL was flanked by two KASP markers, and the primer sequences are shown in Table 4 . When tested in 165 RILs and 150 cultivars and breeding lines, these markers produced the same genotypes as the original SNP probes. In the 150 wheat accessions, Taihemai 5 carried the same alleles of $A X-94588421$ and $A X-94482474$ flanking the QYrqin.nwafu- $2 B L$, and Xinong 364 had the same alleles as QN142 in the QYrqin.nwafu-6BS region. Pedigree analysis showed that Taihemai 5 (Luo 5418/ Zhengmai 7698), QN142 (Zhengmai 8329/Zhi 87135-2-1-2-9), Zhengmai 8329 (Xinong 78[6]9-2/Xinong 80[6]5-6-10), and Xinong 364 may have common wheat genotypes in their pedigrees.

Comparisons with other genes/QTLs. To compare QYrqin. nwafu-2AL with $Y r 32,48$ SNP markers that covered a 6.5-Mb (from the 711.08 to $717.58 \mathrm{Mb}$ positions) genomic region encompassing the QYrqin.nwafu-2AL locus were used to genotype AvSYr32NIL (Yr32). Among the 48 markers, 43 had different genotypes, thereby indicating that QYrqin.nwafu-2AL is different from Yr32 (Supplementary Table S7). Similarly, 35 SNP markers that covered a $20.5-\mathrm{Mb}$ (92.47 to $112.98 \mathrm{Mb}$ ) genomic region harboring QYrqin.nwafu-6BS were used to genotype Stephens, RSL65, and Pingyuan 50, for which 21, 22, and 35 markers were different, respectively. These results indicated that QYrqin.nwafu-6BS is a distinct QTL.

\section{Discussion}

Wheat cultivar QN142 was found to have high-level APR to stripe rust in fields despite its susceptible reactions to the predominant $P$. striiformis f. sp. tritici races such as CYR32 and CYR33, but it was resistant to some old races such as CYR23 at the seedling stage when tested in a greenhouse (Zeng et al. 2014). In the present study, we mapped two genes for ASR to CYR23, but they were not detected in the field experiments, apparently because races such as CYR32 and CYR33 circumvent the race-specific resistance genes. Based on the field data, four genes were estimated using Wright's formula. The estimated number of genes was consistent with the QTL mapping results for the four QTLs identified by ICIM analysis across the six environments. Lan et al. (2015) reported that the numbers of genes estimated using the $\chi^{2}$ method and Wright's method were similar to the number of QTLs detected by QTL mapping, although with a slight difference. However, previous studies have reported that qualitative methods normally underestimate the number of resistance

Table 2. Correlation coefficients $(r)$ of the mean maximum disease severity (MDS) and infection type (IT) for the Avocet $\mathrm{S} \times$ Qinnong 142 recombinant inbred line (RIL) population in six environments

\begin{tabular}{lccccc}
\hline & \multicolumn{5}{c}{$\boldsymbol{r}$ values based on MDS (IT) } \\
\cline { 2 - 6 } Environment $^{\mathbf{b}}$ (location, year) & YL2016 & TS2016 & JY2016 & YL2017 & TS2017 $^{\text {JY2017 }}$ \\
\hline YL2016 & 1 & & & & \\
TS2016 & $0.87(0.86)$ & 1 & & & \\
JY2016 & $0.85(0.84)$ & $0.84(0.83)$ & 1 & 1 & 1 \\
YL2017 & $0.85(0.89)$ & $0.86(0.83)$ & $0.87(0.81)$ & $0.89(0.80)$ & $0.85(0.78)$ \\
TS2017 & $0.87(0.85)$ & $0.86(0.82)$ & $0.88(0.84)$ & $0.87(0.79)$ & 1 \\
JY2017 & $0.82(0.78)$ & $0.81(0.76)$ & $0.83(0.80)$ & & \\
\hline
\end{tabular}

${ }^{a}$ YL, TS, and JY denote Yangling, Tianshui, and Jiangyou, respectively, and 2016 and 2017 represent the RIL populations grown during the 2015-2016 and 2016-2017 cropping seasons, respectively.

${ }^{\mathrm{b}} r$ values calculated with IT are shown in parentheses. All of the $r$ values are significant at $P<0.001$. 
genes in an $\mathrm{F}_{2: 3}$ population compared with QTL analysis (Qiu et al. 2014). This may be caused by the assumptions of additive effects of polygenes and equal contributions of different QTLs to phenotypic variation in disease resistance (Lan et al. 2017; Ren et al. 2017; Wright 1968).

QYrqin.nwafu-1BL was detected near the distal end of chromosome arm 1BL. Several stripe rust APR QTLs have been reported on chromosome 1BL, most of which corresponded to the Yr29/ Lr46 locus (Rosewarne et al. 2013; Singh et al. 1998). Based on the consensus $35 \mathrm{~K}$ and $90 \mathrm{~K}$ map (Allen et al. 2017; Maccaferri et al. 2015), $A X-94642355$ and $I W B 12335$ are the same SNP locus, and the identified QTL region adjoins $Y r 29$. In addition, QN142 and Pavon 76 share the same alleles at the wmc44 and bac17R SSR marker loci, which are linked to Yr29 (Rosewarne et al. 2006). Yr29 is known to be present in many wheat lines such as Pavon 76 developed by CIMMYT, and this locus confers APR to three rust diseases (Herrera-Foessel et al. 2011) and powdery mildew (Lillemo et al. 2008). In previous studies, $\operatorname{Yr} 29$ explained 7 to $65 \%$ of the phenotypic variation in the stripe rust response depending on environmental conditions and genetic background (Lan et al. 2015; Singh et al. 1998). In the present study, QYrqin.nwafu-1BL explained 15.7 to $19.7 \%$ of the variation in stripe rust severity, which was similar to the previously observed results (Ponce-Molina et al. 2018; Ren et al. 2017). Therefore, it is necessary to combine this gene with other APR genes to achieve adequate levels of resistance in the field, as also found with QN142.

The QYrqin.nwafu-2AL QTL was located on chromosome arm 2AL with the flanking markers $A X-94655393$ and $A X$-94895021. Based on the integrated genetic map, six genes or QTLs were reported previously in this region: Yr32 (Eriksen et al. 2004), IWA7339_APR (Zegeye et al. 2014), IWA544_APR (Jighly et al. 2015), QYrns.orz-2AL (Vazquez et al. 2015), QYr.wpg-2A.5 (Naruoka et al. 2015), and QYr.caas-2AL (Liu et al. 2015) (Fig. 2D). In our previous study, wheat line AvSYr32NIL (Yr32) was resistant to $P$. striiformis $\mathrm{f}$. sp. tritici race CYR32 at both the seedling and adult plant stages (DS $=0$ to $40 \%$ ), whereas QN142 was susceptible to CYR32 (Zeng et al. 2014, 2015). In the seedling test, QN142 was resistant to CYR23, but the resistance loci were mapped to $1 \mathrm{DL}$ and $4 \mathrm{AL}$, thereby suggesting that the seedling resistance genes in QN142 are different from $\operatorname{Yr} 32$. Moreover, haplotype comparisons between QN142 and AvSYr32NIL confirmed that the two genes are different. QTL IWA7339_APR derived from synthetic hexaploid wheat, QYrns.orz-2AL in U.S. Pacific Northwest winter wheat cultivar Tubbs, IWA544_APR from a wheat cultivar of ICARDA (International Center for Agricultural Research in Dryland Areas), and QYr.wpg-2A.5 in U.S. Pacific Northwest winter wheat cultivars are all from other countries. QYr.caas-2AL was contributed by Chinese wheat cultivar Zhong 892 with the pedigree of 786-11// Ourou/Beijing 8///LK338/730-04 (Liu et al. 2015). The pedigrees of these gene sources did not indicate obvious relatedness, but further studies are needed to clearly determine the genetic relationships among these genes.

QYrqin.nwafu-2BL mapped to chromosome arm $2 \mathrm{BL}$ and it was flanked by SNP markers $A X-94507002$ and $A X-94562871$, and it was the largest effect QTL in QN142. Several permanently named genes $(Y r 3, Y r 5, Y r 7, Y r 43, Y r 44$, and $Y r 53)$ have been reported on
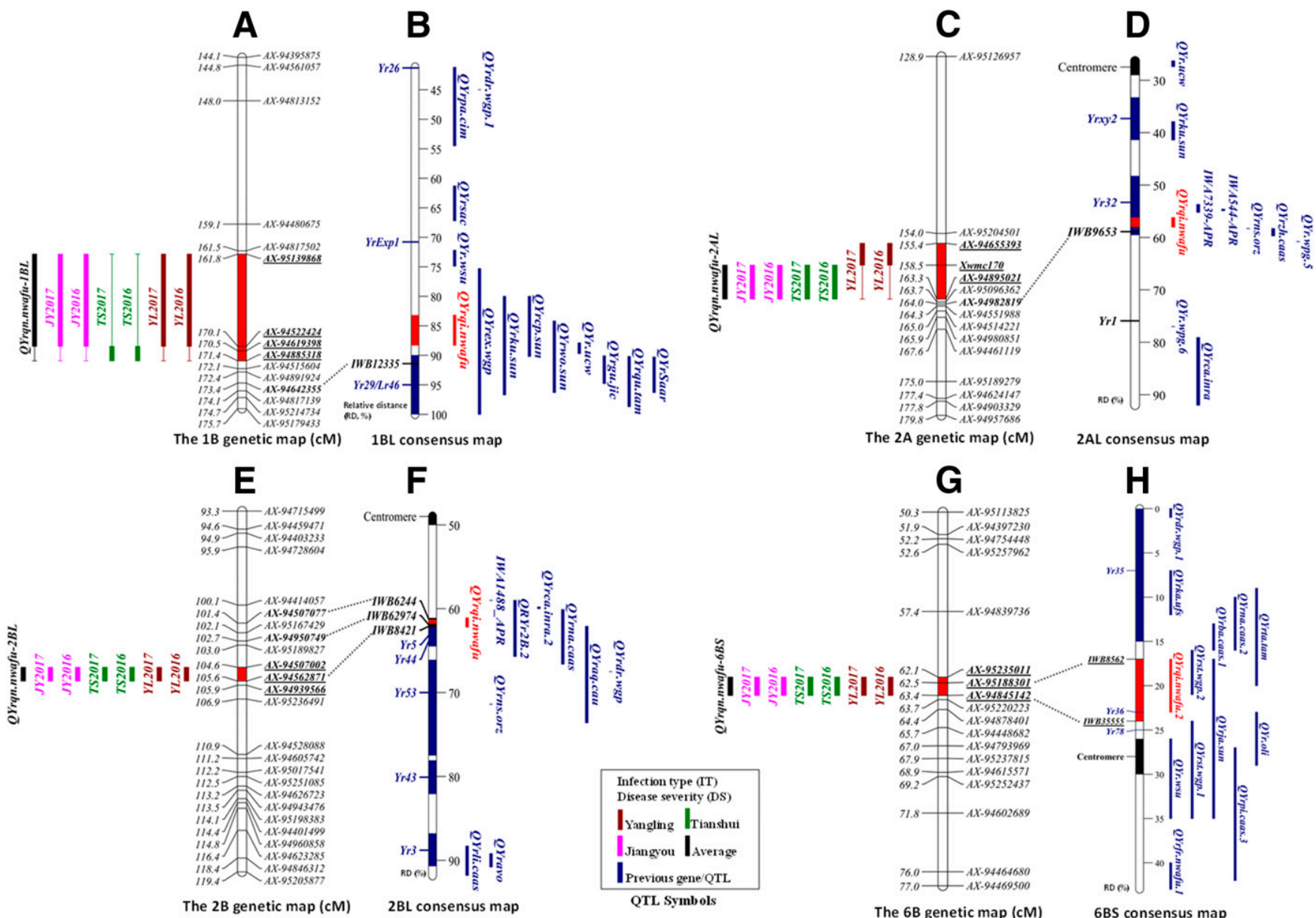

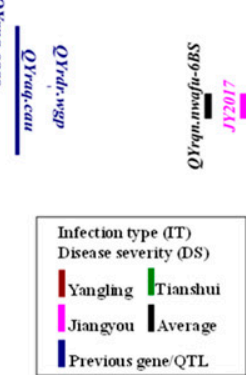

QTL Symbols

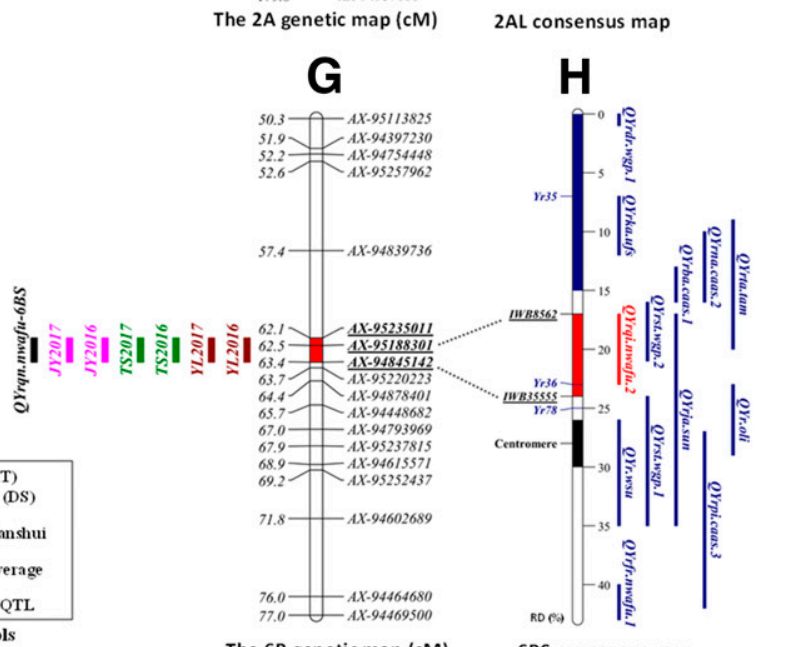

The $6 \mathrm{~B}$ genetic map (cM)

6BS consensus map

Fig. 2. Locations on wheat chromosome arms of quantitative trait loci (QTLs) for stripe rust response in six individual environments. Four linkage groups covering four QTLs for resistance to stripe rust were constructed with simple sequence repeat and single-nucleotide polymorphism markers (A, C, E, and G). The names of the marker loci and the QTLs identified in this study are listed on the left of the linkage groups. The QTLs were identified by inclusive composite interval mapping, and the QTL intervals were associated with a logarithm of odds score $(\mathrm{LOD})>2.0$, with LOD peak values of more than 2.5 determined by permutation tests. The environments where the corresponding QTLs were detected are shown in different colors (B, D, F, and H). The QTLs detected in the present study (colored in red on the corresponding chromosomes) and previously mapped stripe rust resistance genes or QTLs (colored in blue) were positioned based on integrated genetic maps published by Maccaferri et al. (2015) and Bulli et al. (2016). 
chromosome arm 2BL, and they all confer ASR to stripe rust (Maccaferri et al. 2015; Wang and Chen 2017). These genes are ineffective against Chinese $P$. striiformis f. sp. tritici races, except for $Y r 5$ and $Y r 53$ (Zeng et al. 2015). Yr5 is derived from Triticum aestivum ssp. spelta var. album (Macer 1966), and it was mapped onto the interval between SNP markers IWA6121 and IWA4096 (Naruoka et al. 2016), which contains the region of QYrqin.nwafu-2BL. Yr53 is originally from durum wheat PI 480148, and it was flanked by Xwmc441 and XLRRrev/NLRRrev350 (Xu et al. 2013). However, QYrqin.nwafu$2 B L$ confers APR despite having a small effect on the seedling response. In addition, QYrqin.nwafu-2BL shared no marker alleles with $Y r 5$ and Yr53 (data not shown). Based on the resistance types and markers, QYrqin.nwafu-2BL should be different from $Y r 5$ and $Y r 53$. In addition, several stripe rust QTLs on chromosome arm $2 \mathrm{BL}$ have been reported and located in a similar region (Rosewarne et al. 2013), including QYrdr.wgp-2BL in Druchamp (Hou et al. 2015), QYr.caas-2BL in Naxos (Ren et al. 2012b), QYraq.cau-2BL in Aquileja (Guo et al. 2008), and QYr.inra-2BL in Camp Remy (Mallard et al. 2005). QYrdr.wgp-2BL was a minor QTL that explained 4.0 to $10.8 \%$ of the phenotypic variance, and its linked SNP marker was IWA7583 (Hou et al. 2015). QYr.caas-2BL also had a minor effect, and it was detected in a larger interval between SSR markers Xwmc441 and Xwmc361 (Ren et al. 2012b). QYraq.cau-2BL accounted for $61.5 \%$ of the phenotypic variance, and it was located in the marker interval Xwmc175 to Xwmc332 (Guo et al. 2008). QYr.inra-2BL accounted for up to $61 \%$ of the phenotypic variance, and it was flanked by Xbarc101 and Xgwm120 (Mallard et al. 2005). Based on the consensus $35 \mathrm{~K}$ and $90 \mathrm{~K}$ maps, IWA7583 linked to QYrqin.nwafu-2BL was more

Table 3. Summary of stripe rust resistance quantitative trait loci (QTLs) detected in the Avocet $\mathrm{S} \times$ Qinnong 142 recombinant inbred line population across six environments $^{\mathrm{a}}$

\begin{tabular}{|c|c|c|c|c|c|c|c|c|}
\hline \multirow[b]{2}{*}{ QTL } & \multirow[b]{2}{*}{ Environment $^{\mathbf{b}}$} & \multirow[b]{2}{*}{ Marker interval } & \multicolumn{3}{|c|}{ Infection type } & \multicolumn{3}{|c|}{ Maximum disease severity } \\
\hline & & & LOD & Add & PVE & LOD & Add & PVE \\
\hline \multirow[t]{7}{*}{ QYrqn.nwafu-1BL } & YL2016 & $A X-95139868-A X-94522424$ & 8.9 & -0.7 & 17.0 & 6.3 & -9.2 & 11.1 \\
\hline & TS2016 & $A X-95139868-A X-94522424$ & 6.7 & -0.8 & 12.0 & 6.1 & -8.0 & 11.2 \\
\hline & JY2016 & $A X-95139868-A X-94522424$ & 10.5 & -0.7 & 14.3 & 15.6 & -11.6 & 25.3 \\
\hline & YL2017 & $A X-95139868-A X-94522424$ & 5.3 & -0.7 & 9.2 & 16.4 & -9.6 & 17.4 \\
\hline & TS2017 & $A X-94619398-A X-94885318$ & 7.9 & -0.6 & 14.7 & 13.1 & -7.9 & 16.2 \\
\hline & JY2017 & $A X-95139868-A X-94522424$ & 9.0 & -0.6 & 16.7 & 8.7 & -9.2 & 14.8 \\
\hline & Mean & $A X-95139868-A X-94522424$ & 8.5 & -0.7 & 15.7 & 9.3 & -9.3 & 19.7 \\
\hline \multirow[t]{7}{*}{ QYrqn.nwafu-2AL } & YL2016 & $A X-94655393-X w m c 170$ & 15.5 & -0.8 & 18.2 & 14.2 & -8.8 & 19.8 \\
\hline & TS2016 & Xwmc170-AX-94895021 & 10.2 & -0.7 & 9.8 & 11.8 & -8.8 & 13.5 \\
\hline & JY2016 & Xwmc170-AX-94895021 & 4.2 & -0.4 & 9.1 & 7.8 & -6.5 & 10.6 \\
\hline & YL2017 & $A X-94655393-X w m c 170$ & 11.6 & -0.7 & 9.3 & 10.1 & -8.3 & 12.8 \\
\hline & TS2017 & $X w m c 170-A X-94895021$ & 4.3 & -0.5 & 8.5 & 8.8 & -5.9 & 13.8 \\
\hline & JY2017 & $X w m c 170-A X-94895021$ & 4.1 & -0.4 & 8.3 & 7.2 & -6.5 & 18.7 \\
\hline & Mean & $X w m c 170-A X-94895021$ & 9.8 & -0.6 & 11.4 & 14.6 & -7.5 & 12.5 \\
\hline \multirow[t]{7}{*}{ QYrqn.nwafu- $2 B L$} & YL2016 & $A X-94507002-A X-94562871$ & 17.6 & -1.0 & 31.6 & 22.6 & -10.7 & 29.7 \\
\hline & TS2016 & $A X-94507002-A X-94562871$ & 18.2 & -0.9 & 25.7 & 21.1 & -11.5 & 22.9 \\
\hline & JY2016 & $A X-94507002-A X-94562871$ & 26.6 & -1.3 & 39.1 & 17.6 & -11.8 & 25.9 \\
\hline & YL2017 & $A X-94507002-A X-94562871$ & 20.2 & -1.1 & 24.1 & 18.9 & -12.7 & 30.0 \\
\hline & TS2017 & $A X-94507002-A X-94562871$ & 13.8 & -0.8 & 27.4 & 14.6 & -8.4 & 18.3 \\
\hline & JY2017 & $A X-94507002-A X-94562871$ & 8.7 & -0.6 & 15.5 & 9.8 & -7.5 & 23.1 \\
\hline & Mean & $A X-94507002-A X-94562871$ & 17.7 & -0.9 & 24.1 & 14.3 & -11.1 & 27.8 \\
\hline \multirow[t]{7}{*}{ QYrqn.nwafu-6BS } & YL2016 & $A X-95188301-A X-94845142$ & 11.0 & -0.7 & 14.3 & 16.6 & -9.3 & 22.2 \\
\hline & TS2016 & $A X-95235011-A X-95188301$ & 18.4 & -0.9 & 15.4 & 18.3 & -13.1 & 30.0 \\
\hline & JY2016 & $A X-95235011-A X-95188301$ & 14.7 & -0.8 & 14.2 & 11.8 & -9.9 & 18.2 \\
\hline & YL2017 & $A X-95235011-A X-95188301$ & 17.8 & -1.3 & 31.0 & 15.3 & -11.6 & 25.2 \\
\hline & TS2017 & $A X-95235011-A X-95188301$ & 17.1 & -0.9 & 30.6 & 18.9 & -8.5 & 35.1 \\
\hline & JY2017 & $A X-95235011-A X-95188301$ & 11.5 & -1.0 & 21.2 & 9.9 & -8.8 & 13.5 \\
\hline & Mean & $A X-95235011-A X-95188301$ & 14.2 & -0.8 & 20.1 & 19.3 & -9.9 & 22.2 \\
\hline
\end{tabular}

${ }^{\mathrm{a}} \mathrm{LOD}=$ logarithm of odds score; Add = additive effect of the resistance allele (negative signs indicate the resistance allele from QN142); and PVE = percentages of the phenotypic variance explained by individual QTL.

${ }^{\mathrm{b}}$ YL, TS, and JY denote Yangling, Tianshui and Jiangyou, respectively, and 2016 and 2017 represent the field experiments during the 2015-2016 and 2016-2017 cropping seasons, respectively.

A

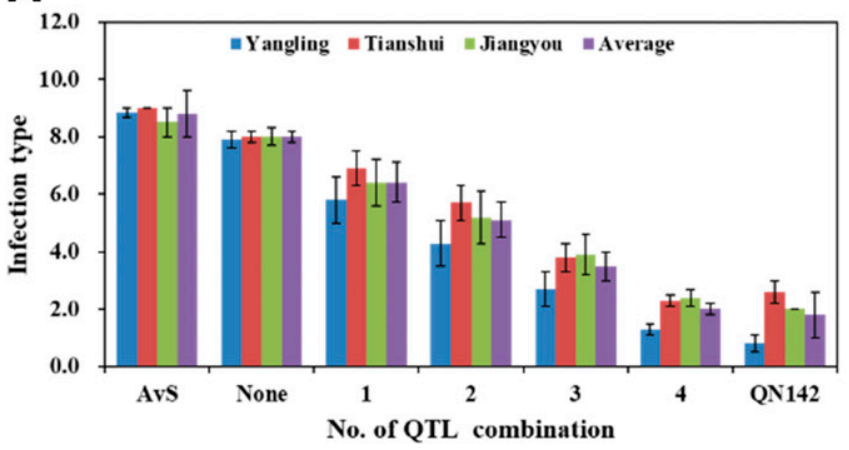

B

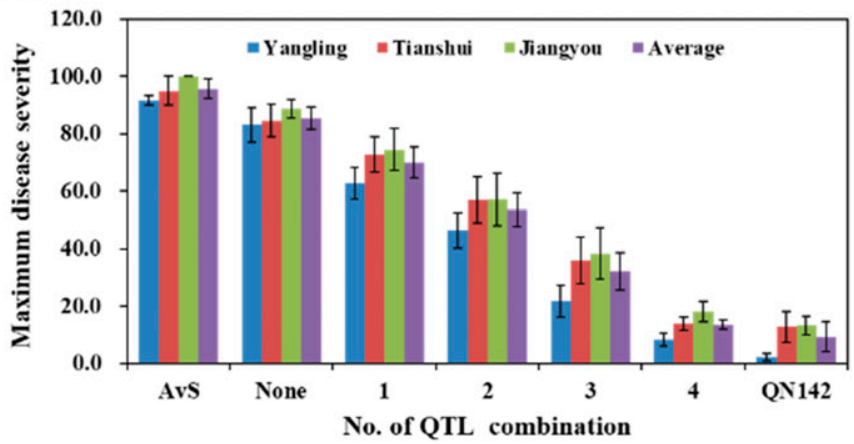

Fig. 3. Effects of quantitative trait locus (QTL) combinations on stripe rust scores according to the mean infection type (A) and maximum disease severity (B) for the recombinant inbred lines from Avocet S (AvS) × Qinnong 142 (QN142) in Yangling, Tianshui, and Jiangyou. 
than $15 \mathrm{cM}$ away from IWB8421 (=AX-94562871), QYr.caas-2BL covered the QYrqin.nwafu-2BL region, and QYraq.cau- $2 B L$ and QYr.inra-2BL were in a close proximity to QYrqin.nwafu- $2 B L$. These findings indicate that QYrqin.nwafu- $2 B L$ is the same as one or both of the other QTLs in this chromosomal region. Allelism tests are needed to clearly determine their genetic relationships.

Chromosome arm 6BS is a resistance gene-rich region that includes many genes or QTLs for stripe rust resistance (Rosewarne et al. 2013; Wang and Chen 2017). Based on an integrated genetic map (Bulli et al. 2016; Maccaferri et al. 2015; Wang and Chen 2017), most of them were concentrated in the interval of 29.2 to $49.0 \mathrm{cM}$, such as QYr.tam-6BS in TAM 111 (Basnet et al. 2014), QYr.caas-6BS.2 in Naxos (Ren et al. 2012b), QYr.caas-6BS in Bainong 64 (Ren et al. 2012c), QYrste.wgp-6BS.2 in Stephens (Santra et al. 2008), QYr.sun-6BS in Janz (Bariana et al. 2010), QYr-6B in Oligoculm (Suenaga et al. 2003), Yr36 in RSL65 (Uauy et al. 2005), QYr.wsu-6B.1 (Bulli et al. 2016), QYr.ucw-6B in PI 519805 (Dong et al. 2017; Maccaferri et al. 2015), QYr.wgp-6B.1 in Stephens (Naruoka et al. 2015; Santra et al. 2008), and $Q Y r$. caas-6BS in Pingyuan 50 (Lan et al. 2010). Some QTLs were identified by genome-wide association analysis (Bulli et al. 2016; Maccaferri et al. 2015; Naruoka et al. 2015), whereas the others were mapped using the biparental mapping approach (Bariana et al. 2010; Basnet et al. 2014; Dong et al. 2017; Ren et al. 2012a, b; Santra et al. 2008; Suenaga et al. 2003; Uauy et al. 2005). After validating $Q Y$ r.ucw- $6 B$ in 10 biparental populations, Dong et al. (2017) suggested that QYr.sun-6BS in Janz, QYr.wgp-6B.1 in Stephens, and $Q Y$ r.wsu- $6 B .1$ could be designated as synonymous with QYr.ucw-6B (named as Yr78). QYrqin.nwafu-6BS was also located in a similar region, but according to the haplotypes, QYrqin.nwafu$6 B S$ was different from the QTLs in Stephens, RSL65, and Pingyuan 50. Both QYr.tam-6B and QYr.caas-6BS had minor effects, in which they explained less than $10 \%$ of the phenotypic variation, but the former was detectable in only some environments, whereas $Q Y r$. caas- $6 B S$ was stable across all the test environments. Based on the different haplotypes of the gene sources and the stability of their effects, QYrqin.nwafu-6BS is probably different from the other QTLs on 6BS. Moreover, none of the markers that flanked these QTLs exhibited polymorphisms in the QN142 mapping population. Therefore, $Q Y r$ qin.nwafu-6BS identified in QN142 is a distinct QTL. Further studies are required to dissect the chromosomal region and confirm the genetic relationships among the stripe rust resistance genes or QTLs on 6BS.

The four QTLs identified in QN142 provide different levels of APR. QYrqin.nwafu-2BL and QYrqin.nwafu-6BS, which each consistently explained up to $30 \%$ of the phenotypic variation, are more useful than the other two QTLs with smaller effects for breeding wheat cultivars with resistance to stripe rust. However, the smalleffect QTLs identified in this study can enhance resistance when combined with other QTLs. RILs with more QTLs had higher levels of resistance, and those with all four QTLs had a similar level of resistance to QN142. Thus, the high level of APR in QN142 is controlled by the combination of the four stable QTLs. Therefore, combining different QTLs is an effective approach for developing wheat cultivars with an adequate level of resistance. QN142 has been grown widely in the Yellow and Huai River Valley wheat zone, and it has remained resistant since its release in 2005, so its APR appears to be durable. The durability can be determined by continually growing QN142 and its derivative cultivars with similar level of resistance. In addition, the QTLs from QN142 can be used together with other effective stripe rust resistance genes in breeding programs to develop more cultivars with different combinations of diverse genes.

Breeding programs are increasingly using MAS to accelerate the selection process and increase the total genetic gains. In the present study, the SNP markers with tight linkage to four stable QTLs for stripe rust resistance provide an opportunity to pyramid these genes with other genes using MAS. When combined with tests using different wheat cultivars, the designed KASP markers linked to all four QTLs were reliable for MAS. The intervals of the two QTLs with the largest effects, QYrqin. nwafu-2BL and QYrqin.nwafu-6BS, were only 1.4 and $0.3 \mathrm{cM}$. Using the flanking markers, we detected these two genes in wheat cultivars related to QN142. We also found that the flanking markers of the four stable QTLs were highly polymorphic among the wheat cultivars and breeding lines, thereby allowing the incorporation of these genes into other backgrounds to develop new cultivars through MAS. All of these markers are codominant, which allows the distinction between heterozygous and homozygous plants. Therefore, the codominant markers can

Table 4. Primer sequences of KASP markers developed based on single-nucleotide polymorphism (SNP) markers with close linkages to stripe rust resistance quantitative trait loci (QTLs) ${ }^{\mathrm{a}}$

\begin{tabular}{|c|c|c|}
\hline SNP name & QTL name & Primer sequence $\left(5^{\prime}-3^{\prime}\right)$ \\
\hline AX-94509279_A & QYrqin.nwafu-1BL & GAAGGTGACCAAGTTCATGCTGGCCAGGAAGAACTGTGAAATT \\
\hline AX-94509279_B & QYrqin.nwafu- $1 B L$ & GAAGGTCGGAGTCAACGGATTGGCCAGGAAGAACTGTGAAATG \\
\hline AX-94509279_C & QYrqin.nwafu- $1 B L$ & CAAAGCATCACTGTGGCCTC \\
\hline AX-94673495_A & QYrqin.nwafu- $1 B L$ & GAAGGTGACCAAGTTCATGCTAAGCTGCATGAGATTGCTACA \\
\hline AX-94673495_B & QYrqin.nwafu- $1 B L$ & GAAGGTCGGAGTCAACGGATTAAGCTGCATGAGATTGCTACG \\
\hline AX-94673495_C & QYrqin.nwafu- $1 B L$ & ACTACAATGTACCTGATGAATCCCC \\
\hline AX-94992915_A & QYrqin.nwafu- $2 A L$ & GAAGGTGACCAAGTTCATGCTGCAAACTCCAACTTCTCCTTG \\
\hline AX-94992915_B & QYrqin.nwafu-2AL & GAAGGTCGGAGTCAACGGATTGCAAACTCCAACTTCTCCTTC \\
\hline AX-94992915_C & QYrqin.nwafu- $2 A L$ & AGAGGGAGAGCTCGAAACTC \\
\hline AX-94757208_A & QYrqin.nwafu- $2 A L$ & GAAGGTGACCAAGTTCATGCTTGCTTGATAGGTGGGAGTGG \\
\hline AX-94757208_B & QYrqin.nwafu- $2 A L$ & GAAGGTCGGAGTCAACGGATTTGCTTGATAGGTGGGAGTGA \\
\hline AX-94757208_C & QYrqin.nwafu- $2 A L$ & TGCAACAAAAGAAAGGCAGCT \\
\hline AX-94588421_A & QYrqin.nwafu- $2 B L$ & GAAGGTGACCAAGTTCATGCTCGGCGGAGGGATCGAACT \\
\hline AX-94588421_B & QYrqin.nwafu- $2 B L$ & GAAGGTCGGAGTCAACGGATTCGGCGGAGGGATCGAACC \\
\hline AX-94588421_C & QYrqin.nwafu- $2 B L$ & CTCTCTCATCTCGCCGAAC \\
\hline AX-94482474_A & QYrqin.nwafu- $2 B L$ & GAAGGTGACCAAGTTCATGCTTGGAGCTTCCGGTGTAGAAG \\
\hline AX-94482474_B & QYrqin.nwafu- $2 B L$ & GAAGGTCGGAGTCAACGGATTTGGAGCTTCCGGTGTAGAAC \\
\hline AX-94482474_C & QYrqin.nwafu- $2 B L$ & TCCTCTTTTGGACACGGCAG \\
\hline AX-95134713_A & QYrqin.nwafu-6BS & GAAGGTGACCAAGTTCATGCTAACCCTTGATCACATCAGCA \\
\hline AX-95134713_B & QYrqin.nwafu-6BS & GAAGGTCGGAGTCAACGGATTAACCCTTGATCACATCAGCG \\
\hline AX-95134713_C & QYrqin.nwafu-6BS & GGGAGGATGTAGTACCGAATGT \\
\hline AX-94839736_A & QYrqin.nwafu-6BS & GAAGGTGACCAAGTTCATGCTTCATGTAGAACTGTTGTTGTCGG \\
\hline AX-94839736_B & QYrqin.nwafu-6BS & GAAGGTCGGAGTCAACGGATTTCATGTAGAACTGTTGTTGTCGC \\
\hline AX-94839736_C & QYrqin.nwafu-6BS & AAGGTTGGAAGATGCGAGAATA \\
\hline
\end{tabular}

${ }^{a}$ KASP $=$ kompetitive allele-specific polymerase chain reaction. KASP markers at the end of the SNP name: A = primers with the added fluorescein amidite adapter; $\mathrm{B}=$ primers with the added hexachloro-fluorescein adapter; and $\mathrm{C}=$ common primers. 
be used for directly selecting homozygous resistant plants in the early generations to speed up the breeding process.

\section{Literature Cited}

Allen, A. M., Barker, G. L. A., Wilkinson, P., Burridge, A., Winfield, M., Coghill, J., Uauy, C., Griffiths, S., Jack, P., Berry, S., Werner, P., Melichar, J. P. E., McDougall, J., Gwilliam, R., Robinson, P., and Edwards, K. J. 2013. Discovery and development of exome-based, co-dominant single nucleotide polymorphism markers in hexaploid wheat (Triticum aestivum L.). Plant Biotechnol. J. 11:279-295.

Allen, A. M., Winfield, M. O., Burridge, A. J., Downie, R. C., Benbow, H. R., Barker, G. L. A., Wilkinson, P. A., Coghill, J., Waterfall, C., Davassi, A., Scopes, G., Pirani, A., Webster, T., Brew, F., Bloor, C., Griffiths, S., Bentley, A. R., Alda, M., Jack, P., Phillips, A. L., and Edwards, K. J. 2017. Characterization of a wheat breeders' array suitable for high-throughput SNP genotyping of global accessions of hexaploid bread wheat (Triticum aestivum). Plant Biotechnol. J. 15:390-401.

Bariana, H. S., Bansal, U. K., Schmidt, A., Lehmensiek, A., Kaur, J., Miah, H., Howes, N., and McIntyre, C. L. 2010. Molecular mapping of adult plant stripe rust resistance in wheat and identification of pyramided QTL genotypes. Euphytica 176:251-260.

Basnet, B. R., Ibrahim, A. M. H., Chen, X. M., Singh, R. P., Mason, E. R., Bowden, R. L., Liu, S. Y., Hays, D. B., Devkota, R. N., Subramanian, N. K., and Rudd, J. C. 2014. Molecular mapping of stripe rust resistance in hard red winter wheat TAM 111 adapted to the U.S. high plains. Crop Sci. 54:1361-1373.

Beddow, J. M., Pardey, P. G., Chai, Y., Hurley, T. M., Kriticos, D. J., Braun, H., Park, R. F., Cuddy, W. S., and Yonow, T. 2015. Research investment implications of shifts in the global geography of wheat stripe rust. Nat. Plants 1:1-5.

Boyd, L. A. 2005. Can Robigus defeat an old enemy?-Yellow rust of wheat. J. Agric. Sci. 143:233-243.

Bulli, P., Zhang, J., Chao, S., Chen, X., and Pumphrey, M. 2016. Genetic architecture of resistance to stripe rust in a global winter wheat germplasm collection. G3 (Bethesda) 6:2237-2253

Cavanagh, C. R., Chao, S., Wang, S., Huang, B. E., Stephen, S., Kiani, S., Forrest, K., Saintenac, C., Brown-Guedira, G. L., Akhunova, A., See, D., Bai, G., Pumphrey, M., Tomar, L., Wong, D., Kong, S., Reynolds, M., Da Silva, M. L., Bockelman, H., Talbert, L., Anderson, J. A., Dreisigacker, S., Baenziger, S., Carter, A., Korzun, V., Morrell, P. L., Dubcovsky, J., Morell, M. K., Sorrells, M. E., Hayden, M. J., and Akhunov, E. 2013. Genome-wide comparative diversity uncovers multiple targets of selection for improvement in hexaploid wheat landraces and cultivars. Proc. Nat. Acad. Sci. 110:8057-8062.

Chen, X. M. 2005. Epidemiology and control of stripe rust [Puccinia striiformis $\mathrm{f}$. sp. tritici] on wheat. Can. J. Plant Pathol. 27:314-337.

Chen, X. M. 2013. High-temperature adult-plant resistance, key for sustainable control of stripe rust. Am. J. Plant Sci. 4:608-627.

Chen, X. M. 2014. Integration of cultivar resistance and fungicide application for control of wheat stripe rust. Can. J. Plant Pathol. 36:311-326.

Chen, X. M., Line, R. F., and Leung, H. 1998. Genome scanning for resistancegene analogs in rice, barley, and wheat by high-resolution electrophoresis. Theor. Appl. Genet. 97:345-355.

Colasuonno, P., Gadaleta, A., Giancaspro, A., Nigro, D., Giove, S., Incerti, O., Mangini, G., Signorile, A., Simeone, R., and Blanco, A. 2014. Development of a high-density SNP-based linkage map and detection of yellow pigment content QTL in durum wheat. Mol. Breed. 34:1563-1578.

Dong, Z., Hegarty, J. M., Zhang, J., Zhang, W., Chao, S., Chen, X., Zhou, Y., and Dubcovsky, J. 2017. Validation and characterization of a QTL for adult plant resistance to stripe rust on wheat chromosome arm 6BS (Yr78). Theor. Appl. Genet. 130:2127-2137.

Eriksen, L., Afshari, F., Christiansen, M. J., McIntosh, R. A., Jahoor, A., and Wellings, C. R. 2004. Yr32 for resistance to stripe rust present in the wheat cultivar Carstens V. Theor. Appl. Genet. 108:567-575.

Fu, D., Uauy, C., Distelfeld, A., Blechl, A., Epstein, L., Chen, X., Sela, H., Fahima, T., and Dubcovsky, J. 2009. A kinase-START gene confers temperaturedependent resistance to wheat stripe rust. Science 323:1357-1360.

Guo, Q., Zhang, Z. J., Xu, Y. B., Li, G. H., Feng, J., and Zhou, Y. 2008. Quantitative trait loci for high-temperature adult-plant and slow-rusting resistance to Puccinia striiformis f. sp. tritici in wheat cultivars. Phytopathology 98:803-809.

Gupta, P. K., Mir, R. R., Mohan, A., and Kumar, J. 2008. Wheat genomics: Present status and future prospects. Int. J. Plant Genomics 2008:896451.

Herrera-Foessel, S. A., Lagudah, E. S., Huerta-Espino, J., Hayden, M. J., Bariana, H. S., Singh, D., and Singh, R. P. 2011. New slow-rusting leaf rust and stripe rust resistance genes Lr67 and $\mathrm{Yr} 46$ in wheat are pleiotropic or closely linked. Theor. Appl. Genet. 122:239-249.

Hou, L., Chen, X., Wang, M., See, D. R., Chao, S., Bulli, P., and Jing, J. 2015. Mapping a large number of QTL for durable resistance to stripe rust in winter wheat Druchamp using SSR and SNP markers. PLoS One 10:e0126794.

Hovmøller, M. S., Walter, S., and Justesen, A. F. 2010. Escalating threat of wheat rusts. Science 329:369.

Jia, J., and Zhao, G. 2016. Wheat 660K SNP array developed by CAAS. 2016. https:// wheat.pw.usda.gov/ggpages/topics/Wheat660_SNP_array_developed_by_ CAAS.pdf

Jighly, A., Oyiga, B. C., Makdis, F., Nazari, K., Youssef, O., Tadesse, W., Abdalla, O., and Ogbonnaya, F. C. 2015. Genome-wide DArT and SNP scan for QTL associated with resistance to stripe rust (Puccinia striiformis $\mathrm{f}$. sp. tritici) in elite ICARDA wheat (Triticum aestivum L.) germplasm. Theor. Appl. Genet. 128:1277-1295.

Johnson, R. 1981. Durable resistance, definition of genetic control, and attainment in plant breeding. Phytopathology 71:567-568.

Lan, C., Basnet, B. R., Singh, R. P., Huerta-Espino, J., Herrera-Foessel, S. A., Ren, Y., and Randhawa, M. S. 2017. Genetic analysis and mapping of adult plant resistance loci to leaf rust in durum wheat cultivar Bairds. Theor. Appl. Genet. 130:609-619.

Lan, C., Liang, S., Zhou, X., Zhou, G., Lu, Q., Xia, X., and He, Z. 2010 Identification of genomic regions controlling adult-plant stripe rust resistance in Chinese landrace Pingyuan 50 through bulked segregant analysis. Phytopathology 100:313-318.

Lan, C., Zhang, Y., Herrera-Foessel, S. A., Basnet, B. R., Huerta-Espino, J., Lagudah, E. S., and Singh, R. P. 2015. Identification and characterization of pleiotropic and co-located resistance loci to leaf rust and stripe rust in bread wheat cultivar Sujata. Theor. Appl. Genet. 128:549-561.

Li, Z. Q., and Zeng, S. M., eds. 2002. Wheat Rust in China. China Agriculture Press, Beijing.

Lillemo, M., Asalf, B., Singh, R. P., Huerta-Espino, J., Chen, X. M., He, Z. H., and Bjørnstad, A. 2008. The adult plant rust resistance loci Lr34/Yr18 and Lr46/ Yr29 are important determinants of partial resistance to powdery mildew in bread wheat line Saar. Theor. Appl. Genet. 116:1155-1166.

Line, R. F., and Qayoum, A. 1992. Virulence, aggressiveness, evolution, and distribution of races of Puccinia striiformis (the cause of stripe rust of wheat) in North America 1968-1987. U.S. Department of Agriculture Technical Bulletin. No. 1788. https://naldc.nal.usda.gov/download/CAT92983836/PDF

Liu, J., He, Z., Wu, L., Bai, B., Wen, W., Xie, C., and Xia, X. 2015. Genome-wide linkage mapping of QTL for adult-plant resistance to stripe rust in a Chinese wheat population Linmai $2 \times$ Zhong 892. PLoS One 10:e0145462.

Long, Y. M., Chao, W. S., Ma, G. J., Xu, S. S., and Qi, L. L. 2017. An innovative SNP genotyping method adapting to multiple platforms and throughputs. Theor. Appl. Genet. 130:597-607.

Maccaferri, M., Zhang, J., Bulli, P., Abate, Z., Chao, S., Cantu, D., Bossolini, E., Chen, X., Pumphrey, M., and Dubcovsky, J. 2015. A genome-wide association study of resistance to stripe rust (Puccinia striiformis f. sp. tritici) in a worldwide collection of hexaploid spring wheat (Triticum aestivum L.). G3 (Bethesda) 5:449-465.

Macer, R. C. F. 1966. The formal and monosomic genetic analysis of stripe rust (Puccinia striiformis) resistance in wheat. Hereditas 2:127-142.

Mallard, S., Gaudet, D., Aldeia, A., Abelard, C., Besnard, A. L., Sourdille, P., and Dedryver, F. 2005. Genetic analysis of durable resistance to yellow rust in bread wheat. Theor. Appl. Genet. 110:1401-1409.

McDonald, B. A., and Linde, C. 2002. Pathogen population genetics, evolutionary potential, and durable resistance. Annu. Rev. Phytopathol. 40:349-379.

McIntosh, R. A. 1992. Close genetic linkage of genes conferring adult-plan resistance to leaf rust and stripe rust in wheat. Plant Pathol. 41:523-527.

McIntosh, R. A., Dubcovsky, J., Rogers, J., Morris, C., Appels, R., and Xia, X. C. 2016. Catalogue of gene symbols for wheat: 2015-2016 Supplement. https:// shigen.nig.ac.jp/wheat/komugi/genes/macgene/supplement2015.pdf

McIntosh, R. A., Dubcovsky, J., Rogers, W. J., Morris, C., and Xia, X. C. 2017 Catalogue of gene symbols for wheat: 2017 Supplement. https://shigen.nig. ac.jp/wheat/komugi/genes/macgene/supplement2017.pdf

McIntosh, R. A., Wellings, R. A., and Park, R. F. 1995. Pages 20-26 in: Wheat Rusts: An Atlas of Resistance Genes. CSIRO, East Melbourne, VIC, Australia.

Meng, L., Li, H., Zhang, L., and Wang, J. 2015. QTL IciMapping: Integrated software for genetic linkage map construction and quantitative trait locus mapping in biparental populations. Crop J. 3:269-283.

Muqaddasi, Q. H., Brassac, J., Börner, A., Pillen, K., and Röder, M. S. 2017. Genetic architecture of anther extrusion in spring and winter wheat. Front. Plant Sci. 8:754.

Naruoka, Y., Ando, K., Bulli, P., Muleta, K. T., Rynearson, S., and Pumphrey, M. O. 2016. Identification and validation of SNP markers linked to the stripe rust resistance gene $\mathrm{Yr} 5$ in wheat. Crop Sci. 56:3055-3065.

Naruoka, Y., Garland-Campbell, K. A., and Carter, A. H. 2015. Genome-wide association mapping for stripe rust (Puccinia striiformis f. sp. tritici) in US Pacific Northwest winter wheat (Triticum aestivum L.). Theor. Appl. Genet. 128:1083-1101

Navabi, A., Tewari, J. P., Singh, R. P., McCallum, B., Laroche, A., and Briggs, K. G. 2005. Inheritance and QTL analysis of durable resistance to stripe and leaf rusts in an Australian cultivar, Triticum aestivum 'Cook'. Genome 48 97-107.

Park, R. F., and Mcintosh, R. A. 1994. Adult plant resistances to Puccinia recondita f. sp. tritici in wheat. N. Z. J. Exp. Agric. 22:151-158.

Peterson, R. F., Campbell, A. B., and Hannah, A. E. 1948. A diagrammatic scale for estimating rust intensity on leaves and stems of cereals. Can. J. Res. Sect. C 26c:496-500.

Ponce-Molina, L. J., Huerta-Espino, J., Singh, R. P., Basnet, B. R., Aguilar-Rincón, V. H., Alvarado, G., Randhawa, M. S., Lan, C. X., Aguilar-Rincón, V. H., Lobato-Ortiz, R., and García-Zavala, J. J. 2018. Characterization of leaf rust and stripe rust resistance in spring wheat 'Chilero'. Plant Dis. 102:421-427.

Qiu, H., Wang, Q., He, Y., Hou, X., Li, L., Guo, W., Kang, Z., and Han, D. 2014. Characterization of resistance to stripe rust and inheritance at adult stage of wheat cultivar Qinnong 142. J. Northwest A\&F Univ. 42:63-68. 
Ramirez-Gonzalez, R. H., Uauy, C., and Caccamo, M. 2015. PolyMarker: A fast polyploid primer design pipeline. Bioinformatics 31:2038-2039.

Rasheed, A., Wen, W., Gao, F., Zhai, S., Jin, H., Liu, J., Guo, Q., Zhang, Y., Dreisigacker, S., Xia, X., and He, Z. 2016. Development and validation of KASP assays for genes underpinning key economic traits in bread wheat. Theor. Appl. Genet. 129:1843-1860.

Ren, R. S., Wang, M. N., Chen, X. M., and Zhang, Z. J. 2012a. Characterization and molecular mapping of $Y r 52$ for high-temperature adult-plant resistance to stripe rust in spring wheat germplasm PI 183527. Theor. Appl. Genet. 125:847-857.

Ren, Y., He, Z., Li, J., Lillemo, M., Wu, L., Bai, B., Lu, Q., Zhu, H., Zhou, G., Du, J., Lu, Q., and Xia, X. 2012b. QTL mapping of adult-plant resistance to stripe rust in a population derived from common wheat cultivars Naxos and Shanghai 3/Catbird. Theor. Appl. Genet. 125:1211-1221.

Ren, Y., Li, Z., He, Z., Wu, L., Bai, B., Lan, C., Wang, C., Zhou, G., Zhu, H., and Xia, X. 2012c. QTL mapping of adult-plant resistances to stripe rust and leaf rust in Chinese wheat cultivar Bainong 64. Theor. Appl. Genet. 125:1253-1262.

Ren, Y., Singh, R. P., Basnet, B. R., Huerta-Espino, J., Lagudah, E. S., PonceMolina, L. J., Lan, C., Huerta-Espino, J., Lagudah, E. S., and Ponce-Molina, L. J. 2017. Identification and mapping of adult plant resistance loci to leaf rust and stripe rust in common wheat cultivar Kundan. Plant Dis. 101:456-463.

Röder, M. S., Korzun, V., Wendehake, K., Plaschke, J., Tixier, M. H., Leroy, P., and Ganal, M. W. 1998. A microsatellite map of wheat. Genetics 149: 2007-2023.

Rosewarne, G. M., Herrera-Foessel, S. A., Singh, R. P., Huerta-Espino, J., Lan, C. X., and He, Z. H. 2013. Quantitative trait loci of stripe rust resistance in wheat. Theor. Appl. Genet. 126:2427-2449.

Rosewarne, G. M., Singh, R. P., Huerta-Espino, J., William, H. M., Bouchet, S., Cloutier, S., McFadden, H., and Lagudah, E. S. 2006. Leaf tip necrosis, molecular markers and $\beta 1$-proteasome subunits associated with the slow rusting resistance genes $L r 46 / Y r 29$. Theor. Appl. Genet. 112:500-508.

Santra, D. K., Chen, X. M., Santra, M., Campbell, K. G., and Kidwell, K. K. 2008. Identification and mapping QTL for high-temperature adult-plant resistance to stripe rust in winter wheat (Triticum aestivum L.) cultivar 'Stephens'. Theor. Appl. Genet. 117:793-802.

Semagn, K., Babu, R., Hearne, S., and Olsen, M. 2014. Single nucleotide polymorphism genotyping using Kompetitive Allele Specific PCR (KASP): Overview of the technology and its application in crop improvement. Mol. Breed. 33:1-14.

Semagn, K., Bjornstad, A., and Xu, Y. 2010. The genetic dissection of quantitative traits in crops. Electron. J. Biotechnol. 13(5).

Singh, R. P., Huerta-Espino, J., and William, H. M. 2005. Genetics and breeding for durable resistance to leaf and stripe rusts in wheat. Turk. J. Agric. For. 29: 121-127.

Singh, R. P., Mujeeb-Kazi, A., and Huerta-Espino, J. 1998. Lr46: A gene conferring slow-rusting resistance to leaf rust in wheat. Phytopathology 88 : 890-894.

Somers, D. J., Isaac, P., and Edwards, K. 2004. A high-density microsatellite consensus map for bread wheat (Triticum aestivum L.). Theor. Appl. Genet. 109:1105-1114.

Song, W. N., Ko, L., and Henry, R. J. 1994. Polymorphisms in the $\alpha$-amy1 gene of wild and cultivated barley revealed by the polymerase chain reaction. Theor. Appl. Genet. 89:509-513.

Sourdille, P., Singh, S., Cadalen, T., Brown-Guedira, G. L., Gay, G., Qi, L., Gill, B. S., Dufour, P., Murigneux, A., and Bernard, M. 2004. Microsatellite-based deletion bin system for the establishment of genetic-physical map relationships in wheat (Triticum aestivum L.). Funct. Integr. Genomics 4:12-25.

St. Clair, D. A. 2010. Quantitative disease resistance and quantitative resistance loci in breeding. Annu. Rev. Phytopathol. 48:247-268.

Suenaga, K., Singh, R. P., Huerta-Espino, J., and William, H. M. 2003. Microsatellite markers for genes $\mathrm{Lr} 34 / \mathrm{Yr} 18$ and other quantitative trait loci for leaf rust and stripe rust resistance in bread wheat. Phytopathology 93: 881-890.

Uauy, C., Brevis, J. C., Chen, X. M., Khan, I., Jackson, L., Chicaiza, O., Distelfeld, A., Fahima, T., and Dubcovsky, J. 2005. High-temperature adult-plant (HTAP) stripe rust resistance gene Yr36 from Triticum turgidum ssp. dicoccoides is closely linked to the grain protein content locus $G p c-B 1$. Theor. Appl. Genet. 112:97-105.

Vazquez, M. D., Zemetra, R., Peterson, C. J., Chen, X. M., Heesacker, A., and Mundt, C. C. 2015. Multi-location wheat stripe rust QTL analysis: Genetic background and epistatic interactions. Theor. Appl. Genet. 128:1307-1318.
Voorrips, R. E. 2002. MapChart: Software for the graphical presentation of linkage maps and QTL. J. Hered. 93:77-78.

Wan, A. M., and Chen, X. M. 2014. Virulence characterization of Puccinia striiformis f. sp. tritici using a new set of $Y r$ single-gene line differentials in the United States in 2010. Plant Dis. 98:1534-1542.

Wan, A. M., Chen, X. M., and He, Z. H. 2007. Wheat stripe rust in China. Crop Pasture Sci. 58:605-619.

Wang, J. 2009. Inclusive composite interval mapping of quantitative trait genes Acta Agron. Sin. 35:239-245.

Wang, M. N., and Chen, X. M. 2017. Stripe rust resistance. Pages 353-558 in: Stripe Rust. X. M. Chen and Z. S. Kang, eds. Springer, Dordrecht, the Netherlands.

Wang, S., Wong, D., Forrest, K., Allen, A., Chao, S., Huang, B. E., Maccaferri, M., Salvi, S., Milner, S. G., Cattivelli, L., Mastrangelo, A. M., Whan, A., Stephen, S., Barker, G., Wieseke, R., Plieske, J., Lillemo, M., Mather, D., Appels, R. Dolferus, R., Brown-Guedira, G., Korol, A., Akhunova, A. R., Feuillet, C., Salse, J., Morgante, M., Pozniak, C., Luo, M., Dvorak, J., Morell, M. Dubcovsky, J., Ganal, M., Tuberosa, R., Lawley, C., Mikoulitch, I., Cavanagh, C., Edwards, K. J., Hayden, M., and Akhunov, E. 2014. Characterization of polyploid wheat genomic diversity using a high-density 90000 single nucleotide polymorphism array. Plant Biotechnol. J. 12:787-796.

Wellings, C. R. 2011. Global status of stripe rust: A review of historical and current threats. Euphytica 179:129-141.

Wiesner-Hanks, T., and Nelson, R. 2016. Multiple disease resistance in plants. Annu. Rev. Phytopathol. 54:229-252.

Winfield, M. O., Allen, A. M., Burridge, A. J., Barker, G. L. A., Benbow, H. R., Wilkinson, P. A., Coghill, J., Waterfall, C., Davassi, A., Scopes, G., Pirani, A., Webster, T., Brew, F., Bloor, C., King, J., West, C., Griffiths, S., King, I., Bentley, A. R., and Edwards, K. J. 2016. High-density SNP genotyping array for hexaploid wheat and its secondary and tertiary gene pool. Plant Biotechnol. J. 14:1195-1206.

Wright, S. 1968. Evolution and the Genetics of Populations, Vol. 1. Genetic and Biometric Foundations. University of Chicago Press, Chicago, IL.

Wu, J., Liu, S., Wang, Q., Zeng, Q., Mu, J., Huang, S., Yu, S., Han, D., and Kang, Z. 2018. Rapid identification of an adult plant stripe rust resistance gene in hexaploid wheat by high-throughput SNP array genotyping of pooled extremes. Theor. Appl. Genet. 131:43-58.

Wu, J., Wang, Q., Chen, X., Liu, S., Li, H., Zeng, Q., Mu, J., Dai, M., Han, D., and Kang, Z. 2017. Development and validation of KASP-SNP markers for QTL underlying resistance to stripe rust in common wheat cultivar P10057. Plant Dis. 101:2079-2087.

Wu, J., Wang, Q., Chen, X., Wang, M., Mu, J., Lv, X., Huang, L., Han, D., and Kang, Z. 2016. Stripe rust resistance in wheat breeding lines developed for central Shaanxi, an overwintering region for Puccinia striiformis f. sp. tritici in China. Can. J. Plant Pathol. 38:317-324.

Xu, L. S., Wang, M. N., Cheng, P., Kang, Z. S., Hulbert, S. H., and Chen, X. M 2013. Molecular mapping of Yr53, a new gene for stripe rust resistance in durum wheat accession PI 480148 and its transfer to common wheat. Theor. Appl. Genet. 126:523-533.

Yan, J. B., Tang, J. H., Meng, Y. J., Ma, X. Q., Teng, W. T., Chander, S., Li, L., and Li, J. S. 2006. Improving QTL mapping resolution based on genotypic sampling-A case using a RIL population. Acta Genet. Sin. 33:617-624.

Yang, H., Li, C., Lam, H. M., Clements, J., Yan, G., and Zhao, S. 2015 Sequencing consolidates molecular markers with plant breeding practice. Theor. Appl. Genet. 128:779-795.

Zegeye, H., Rasheed, A., Makdis, F., Badebo, A., and Ogbonnaya, F. C. 2014 Genome-wide association mapping for seedling and adult plant resistance to stripe rust in synthetic hexaploid wheat. PLoS One 9 e105593.

Zeng, Q., Han, D., Wang, Q., Yuan, F., Wu, J., Zhang, L., Wang, X., Huang, L., Chen, X., and Kang, Z. 2014. Stripe rust resistance and genes in Chinese whea cultivars and breeding lines. Euphytica 196:271-284

Zeng, Q. D., Shen, C., Yuan, F., Wang, Q., Wu, J., Xue, W., Zhan, G., Yao, S., Chen, W., Huang, L. L., Han, D. J., and Kang, Z. S. 2015. The resistance evaluation of the $Y r$ genes to the main prevalent pathotypes of Puccinia striiformis f. sp. tritici in China. Acta Phytopathol. Sin. 45:641-650.

Zhou, X. L., Han, D. J., Chen, X. M., Gou, H. L., Guo, S. J., Rong, L., Wang, Q. L., Huang, L. L., and Kang, Z. S. 2014. Characterization and molecular mapping of stripe rust resistance gene $\mathrm{Yr} 61$ in winter wheat cultivar Pindong 34. Theor Appl. Genet. 127:2349-2358. 